\title{
Silver Nanoparticles Obtained by Aqueous or Ethanolic Aloe vera Extracts: An Assessment of the Antibacterial Activity and Mercury Removal Capability
}

\author{
Ederley Vélez ${ }^{\mathbb{D}},{ }^{1}$ Gloria Campillo ${ }^{\mathbb{D}},{ }^{1}$ Gladis Morales, ${ }^{2}$ César Hincapié, ${ }^{1}$ \\ Jaime Osorio, ${ }^{3}$ and Oscar Arnache ${ }^{3}$ \\ ${ }^{1}$ Facultad de Ciencias Básicas, Grupo de Materiales Nanoestructurados y Biomodelación (MATBIOM), Universidad de Medellín, \\ Medellín, Colombia \\ ${ }^{2}$ Facultad de Ingenierías, Grupo de Investigaciones y Mediciones Ambientales (GEMA), Universidad de Medellín, Medellín, Colombia \\ ${ }^{3}$ Instituto de Física, Facultad de Ciencias Exactas y Naturales, Universidad de Antioquia, Calle 70, No. 52-21, A.A. 1226, \\ Medellín, Colombia
}

Correspondence should be addressed to Gloria Campillo; gecampillo@udem.edu.co

Received 30 October 2017; Revised 12 January 2018; Accepted 14 February 2018; Published 19 March 2018

Academic Editor: Francesco Ruffino

Copyright (C) 2018 Ederley Vélez et al. This is an open access article distributed under the Creative Commons Attribution License, which permits unrestricted use, distribution, and reproduction in any medium, provided the original work is properly cited.

\begin{abstract}
Silver nanoparticles (AgNPs) were synthesized by chemical reduction of $\mathrm{Ag}^{+}$ions (from silver nitrate $\mathrm{AgNO}_{3}$ ), using aqueous or ethanolic Aloe vera extracts as reducing, stabilizing, and size control agent. The nanoparticles' sizes were between 2 and $7 \mathrm{~nm}$ for ethanolic extract and between 3 and $14 \mathrm{~nm}$ for aqueous extract, as measured by High-Resolution Transmission Electron Microscope (HRTEM). The antibacterial activity against a mesophilic microorganism, Kocuria varians, a Gram-positive coccus, was measured by counting bacterial colonies in agar plate for both extracts. We found that $4 \%$ effective concentration is the lowest concentration that completely inhibited visible growth. Mercury removal was investigated by Atomic Absorption Spectroscopy (AAS) measurements, where it was shown that it is not necessary to use high concentrations of nanoparticles for effective removal of mercury inasmuch as with a $20 \% \mathrm{~V} / \mathrm{V}$ concentration of both extracts; the $\mathrm{Hg}$ (II) removal percentage was above $95 \%$. These results show that the mercury remaining unremoved from the different essays is below the level allowed by World Health Organization (WHO) and the Environmental Protection Agency (EPA).
\end{abstract}

\section{Introduction}

The synthesis of nanomaterials is currently one of the most active areas in nanoscience. Special attention has been dedicated to nanomaterials that help improve the human quality life. A remarkable example is the silver nanoparticles (AgNPs) which are known by their inhibitory and bactericidal effects.

AgNPs can be produced with various sizes and shapes depending on the fabrication method which can be physical, chemical, biological, and hybrid. The chemical methods use toxic chemicals, which are not friendly to environment, making them unsuitable for biomedical applications. Specifically, the widely used chemical reduction methods [1] usually employ toxic and perilous chemicals that are responsible for various biological risks. On the other hand, physical methods are expensive and incompatible with sizeable production of nanoparticles. Therefore, to avoid toxic and hazardous chemicals, the green synthesis methods have been developed, attracting significant interest because they are environmentfriendly, rapid, facile, and energy-efficient [2]. Green synthesis using huge biological molecules derived from plant extracts [3] could facilitate size and morphology control of metal nanoparticles due to the presence of an innumerable quantity of biomolecules possessing bioreduction and biostabilization ability [4]. Specifically, many plants have been used for silver nanoparticles synthesis [3,5], such as stem bark of Callicarpa maingayi [6], Terminalia cuneata [7], Illicium verum (star anise) [8], and pod extract of Acacia nilotica [9]. 
Aloe vera extracts have been used for the synthesis of stable AgNPs in several previous articles investigating their antibacterial, antifungal, and mosquitocidal activity [1013]. Aloe vera extracts have substances that lead to steric repulsion between individuals preventing nanoparticles from aggregation [14]. Using Aloe vera as surfactant prevents nuclei aggregation by decreasing the total surface energy because it contains a multitude of chemical constituents such as amino acids, enzymes, minerals, vitamins (A, C, and $\mathrm{E}$ ), anthraquinones, lignin, monosaccharide, polysaccharides, salicylic acid, saponins, sterols, and minerals (calcium, phosphorous, potassium, iron, sodium, magnesium, manganese, copper, chromium, and zinc) [15].

The antibacterial properties of silver have been known since ancient times. It has been used in water and air purification, biomedical application, catalytic activity, household products, cosmetics [18-20], food production [21], and clothing $[22,23]$. Due to its small size and large surface to volume ratios, AgNPs might exhibit additional antimicrobial capabilities not exerted by ionic silver. Compared with their bulk counterparts, silver nanoparticles have both chemical and physical differences in their properties [24].

AgNPs have also been used in the control of blood sugar levels [25], destruction of pesticides [26], and the removal of heavy metal ions such as $\mathrm{Hg}(\mathrm{II}), \mathrm{Hg}(\mathrm{I}), \mathrm{Pb}(\mathrm{II})$, and $\mathrm{Cd}(\mathrm{II})$ from water [27, 28]. Besides, Katok et al. have reported [29] that as the diameter of AgNPs is reduced below $32 \mathrm{~nm}$, mercury(II) is reduced from water onto AgNPs. Esmaielzadeh Kandjani et al. have proposed $\mathrm{ZnO} / \mathrm{Ag}$ nanoarrays, another nanostructured system, to remove $\mathrm{Hg}$ (II) due to its high selectivity because of the unique way in which mercury interacts with Ag nanoparticles [30].

Because mercury is one of the most toxic heavy metals and concerns the threats to environment and human health, other nanostructured systems have been proposed.

This study aims to evaluate the antibacterial activity and the mercury removal capability of AgNPs, which were synthesized by chemical reduction method of silver nitrate (AgNO3), using aqueous or ethanolic Aloe vera extracts as reducing, stabilizing, and size control agent. In a previous work, we reported synthesis of silver nanoparticles using a mixture of polyvinylpyrrolidone (PVP)-Aloe vera, as reducing and stabilizing agent, in order to control the particle size [31]. The morphology and particle size distribution were characterized by Transmission Electron Microscope (TEM); the antibacterial activity against mesophilic microorganism, Kocuria varians, a Gram-positive coccus, was measured by counting bacterial colonies in agar plate, while mercury removal was investigated by Atomic Absorption Spectroscopy (AAS) measurements.

\section{Materials and Methods}

2.1. Materials. Analytical grade silver nitrate $\left(\mathrm{AgNO}_{3}\right)$, ethanol absolute, sodium hydroxide $(\mathrm{NaOH})$, sodium borohydride $\left(\mathrm{NaBH}_{4}\right)$, and hydrochloric acid $(\mathrm{HCl})$ were purchased from Merck KGaA and mercury standard solution (Panreac) $\mathrm{Hg}=1.000 \pm 0.002 \mathrm{mg} / \mathrm{L}$. The reagents were used as received.
2.2. Aloe vera Extracts Preparation. $15 \mathrm{~g}$ of inner leaf juice of Aloe vera leaves was heated at $80^{\circ} \mathrm{C}$ for 1 hour and then dried. It was used for both aqueous and ethanolic extracts, using a ratio of $0.1: 3$, dry material to solvent. The resulting extracts were used in all synthesis after being filtered by gravity.

2.3. Preparation of Silver Nanoparticles (AgNPs). The AgNPs were prepared by chemical reduction of an aqueous solution, $12 \mathrm{mM}$ of $\mathrm{AgNO}_{3} .50 \mathrm{~mL}$ of this solution is added to $30 \mathrm{~mL}$ of either aqueous or ethanolic Aloe vera extract. The whole reaction was carried out in presence of air and constant and neutral $\mathrm{pH}$. The mixture was vigorously stirred at temperature of $57^{\circ} \mathrm{C}$ during $3 \mathrm{~h}$ and then heated $2^{\circ} \mathrm{C} / \mathrm{min}$ to reach $80^{\circ} \mathrm{C}$ holding for 2 hours until obtaining a translucent solution with small suspended particles that could be removed by simple filtration $(0.45 \mu \mathrm{m})$.

2.4. TEM Measurements. The particle size and morphology of silver nanoparticles were observed by High-Resolution Transmission Electron Microscopy (HRTEM) using a Tecnai F20 Super Twin TMP with field emission source, with resolution of $0.1 \mathrm{~nm}$ at $200 \mathrm{kV}$ and 1.0 maximum magnification TEM MX camera GATAN US 1000XP-P. Samples for TEM measurements were suspended in ethanol and ultrasonically dispersed.

In this study, approximately 483 particles for ethanolic extract (or 93 particles for aqueous extract) were measured from several images using image analysis software (ImageJ) [32]. The histogram obtained was fitted using a Gauss distribution function.

2.5. Antibacterial Activity of Synthesized AgNPs. Initially, the inoculum was prepared using fresh rumen. Thereafter, the nutrient solution was prepared according to Siegert and Banks [33], obtaining a solution with a rumen concentration of $1 \mathrm{~g} / \mathrm{L}$. It was cultured with $10 \mathrm{~mL}$ of the inoculated solution and stirred for 24 hours. Nutrient broth solution according to the manufacturer's recommendation $(8 \mathrm{~g} / \mathrm{L})$ was prepared and spread onto agar plate and incubated at $37^{\circ} \mathrm{C}$ for $6 \mathrm{~h}$. After incubation, the content of microorganisms was evaluated according to the McFarland scale $\left(1.7 \times 10^{8} \mathrm{CFU} / \mathrm{mL}\right)$. The specific bacteria in this solution were identified by microbiological analysis: Kocuria varians, a Gram-positive coccus. This microorganism found in the microbiota skin and mucosae of man and some mammals is responsible for different types of human infection $[34,35]$, brain abscess [36], and urinary infections [37].

To examine the bactericidal activity of AgNPs against Kocuria varians, the agar dilution method was used. It involves the incorporation of varying desired concentrations of the antimicrobial agent into an agar medium, habitually using serial twofold dilutions, followed by the inoculation of a defined microbial inoculum onto the agar plate surface. As nutrient medium, an agar plate count solution was used, which was sterilized at 20 pounds of pressure for 30 minutes in autoclave GEMMYCO SA 232 mark.

In a series of previously sterilized Petri dishes with agar, a solution of AgNPs was added so that the final nanoparticle concentration was $10 \%$. After agar solidification, $0.1 \mathrm{~mL}$ of the 


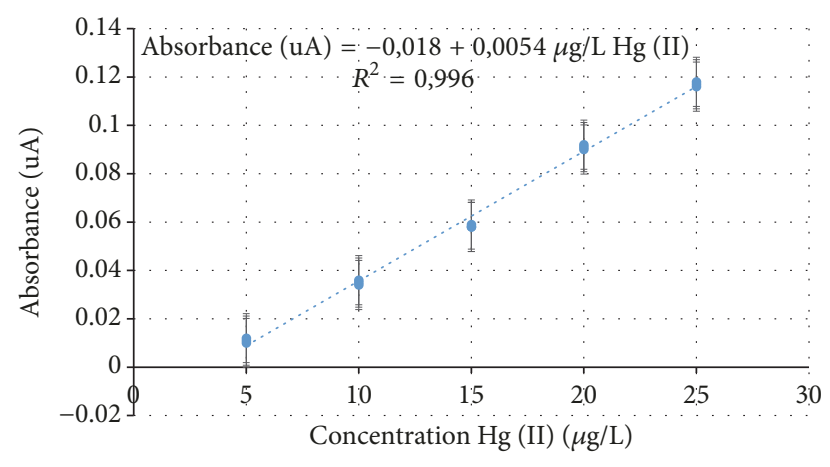

FIGURE 1: Calibration curve to determinate the quantity of $\mathrm{Hg}$ (II), which is a plot of the concentrations of standard $\mathrm{Hg}(\mathrm{II})(\mu \mathrm{g} / \mathrm{L})$ versus the absorbance of $\mathrm{Hg}(\mathrm{II})$ at $253.7 \mathrm{~nm}$.

inoculum was added and the plates were incubated at $37^{\circ} \mathrm{C}$. After incubation, the number of colonies grown on the agar was counted [17]; all this procedure was done in triplicate. It was considered a positive control, which consisted of agar without nanoparticles and inoculated and a negative control which consisted of agar with nanoparticles but not inoculated.

2.6. Mercury Removal Capacity of Synthesized AgNPs. In order to evaluate the mercury removal capability of synthesized nanoparticles, a series of fixed volume dilutions of AgNPs (20, 40, 60, 80, and 100\% V/V) were incorporated in an agar plate count matrix. When each system has been solidified, $2.5 \mathrm{~mL}$ standard solution of mercury, $\mathrm{Hg}(\mathrm{II})$, at different concentrations $(5,10$, and $15 \mathrm{mg} / \mathrm{L})$ was added in triplicate and kept in contact for $24 \mathrm{~h}$. The quantification of $\mathrm{Hg}$ (II) in the solution was carried out by Atomic Absorption Spectrometer (Thermo Scientific ${ }^{\mathrm{TM}}$ CE 3000), fitted with a Thermo Scientific VP100; the steam system uses a solution of sodium borohydride $\left(\mathrm{NaBH}_{4}\right)$ and hydrochloric acid $(\mathrm{HCl})$ to get the complex with the mercury.

The resulting calibration curve (Figure 1) shows that absorbance versus concentration of $\mathrm{Hg}$ (II) is linear over the 5 to $25 \mu \mathrm{g} / \mathrm{L}$ range and is suitable for quantitative work.

\section{Results and Discussion}

Figures 2(a) and 2(b) show TEM micrographs and corresponding size distribution histogram of AgNPs obtained using aqueous and ethanolic Aloe vera extracts, respectively. The TEM image confirms the presence of nanoparticles between 2 and $7 \mathrm{~nm}$ in size for ethanolic extract and between 3 and $14 \mathrm{~nm}$ for aqueous extract. Thus, AgNPs obtained by chemical reduction using ethanolic Aloe vera extract as a surfactant exhibited smaller sizes compared to AgNPs obtained from aqueous Aloe vera extract.

In previous works, stable AgNPs have been synthesized using aqueous Aloe vera extract. Reference [13] found that the AgNPs could be stable for at least three months and SEM analysis revealed that the AgNPs are predominantly spherical with average size of $25 \mathrm{~nm}$. Other authors ([11, 12]) have used also SEM analysis, [12], showing that silver nanoparticles are cubical, rectangular, triangular, and spherical in shape with uniform distribution. The measured sizes of the agglomerated nanoparticles were in the range of $287.5-293.2 \mathrm{~nm}$; however, the average size of an individual particle is estimated to be $70 \mathrm{~nm}$. On the other hand, [11] showed almost spherical and cubic structures with a size range of $35-55 \mathrm{~nm}$. Moreover, Chandran et al. [10] synthesized silver nanoparticles with average size of $15.2 \pm 4.2 \mathrm{~nm}$ as estimated by TEM. Their analysis reveals that the silver nanoparticles are predominantly spherical; nonetheless the reaction proceeded only in the presence of ammonia, which facilitates the formation of a soluble silver complex (diammine silver(I) chloride) that then aids in the reduction.

We find similar results in terms of particle size, demonstrating the effectiveness of Aloe vera extracts as a reducing agent to mediate the green synthesis of silver nanoparticles; additionally, the good dispersibility mainly in ethanolic Aloe vera extract could be explained by a layer of organic material surrounding the synthesized AgNPs, as is shown in TEM images.

The resultant histograms show slight dispersion of the particle size of synthesized AgNPs for both ethanolic and aqueous extract distributions but confirm the presence of nanoparticles with size less than $15 \mathrm{~nm}$ for both extracts, as well as the presence of nanoparticles of greater size but in minimum quantities. These larger diameter AgNPs were vastly outnumbered by those with smaller diameters in the HRTEM images analyzed. Using ethanolic Aloe vera extract, most particles $(\sim 90.5 \%)$ are within a range size between 2 and $6 \mathrm{~nm}$, while $\sim 76.3 \%$ of those using aqueous Aloe vera extract are in this range size. This can be explained by the higher solubility power of ethanol for organic compounds yielding a lower particle size and less polydispersity than water.

The hexagonal patterns observed by electron diffraction (Figure 3) represent a proof of the crystalline nature of the prepared nanoparticles. The hexagonal symmetry of diffraction spots pattern (Scherrer ring pattern) shown in both cases confirmed that the spherical particles are well crystalline, and its face is indexed to (111) planes. The measured lattice spacing ( $\sim 0.235 \mathrm{~nm}$ for both samples), corresponding to (111) planes of silver, is in agreement with previous reports [16]. The enlarged image of the Fast Fourier Transforms of HighResolution Transmission Electron Microscopy, FFT pattern, shows additional diffraction spots that are probably associated with compounds of Aloe vera and ethanolic extracts. The values obtained are summarized in Table 1.

These results are in agreement with the measurement extracted directly from the enlarged micrograph of one particle. The lattice spacings of $0.265 \mathrm{~nm}$ and $0.237 \mathrm{~nm}$, obtained for the aqueous and ethanolic Aloe vera extracts, respectively, were calculated from TEM images (Figure 3) using the ImageJ software [32]. Fringe periods represent metallic fcc Ag phase [38] and correspond to (111) planes of silver.

(i) Antibacterial Activity. The antibacterial activity of AgNPs obtained with both extracts against Kocuria varians was evaluated in triplicate using the agar dilution method, which involves the incorporation of varying desired concentrations of the antimicrobial agent $(20,40,60,80$, and $100(\% \mathrm{~V} / \mathrm{V})$ 

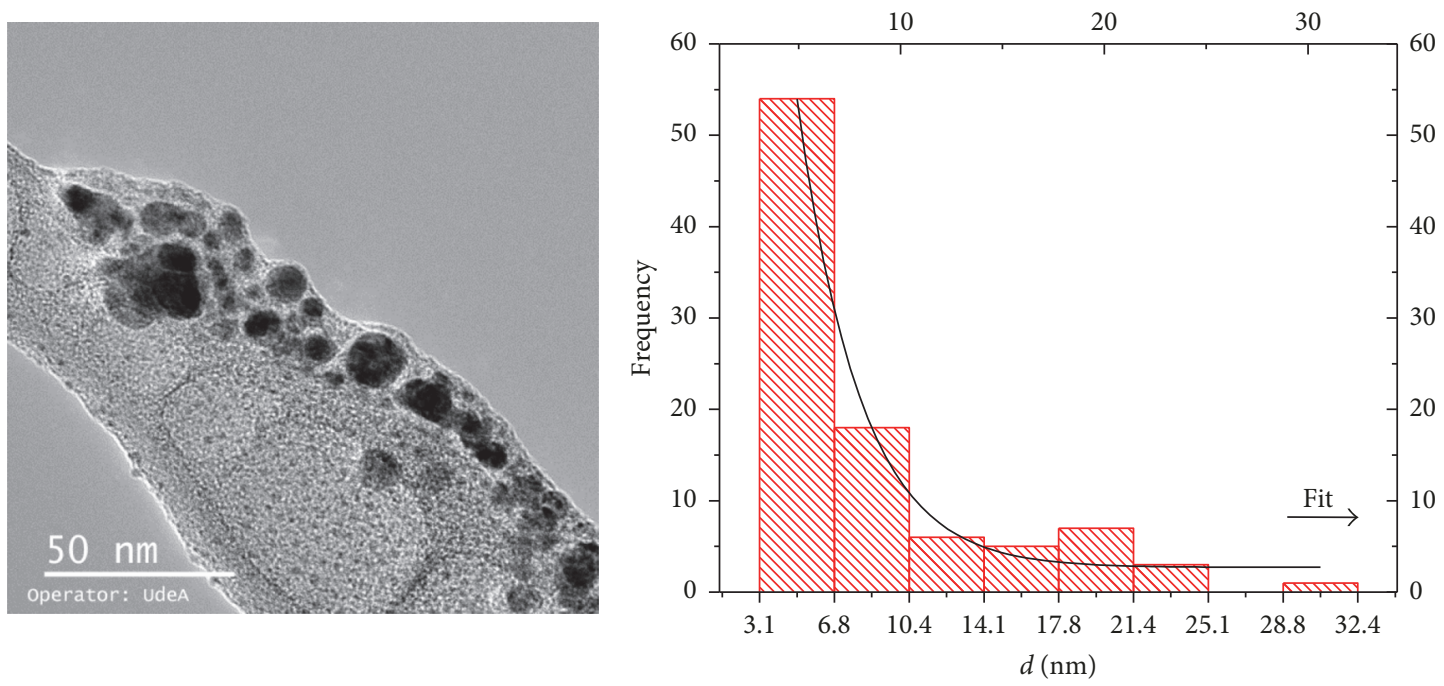

(a)
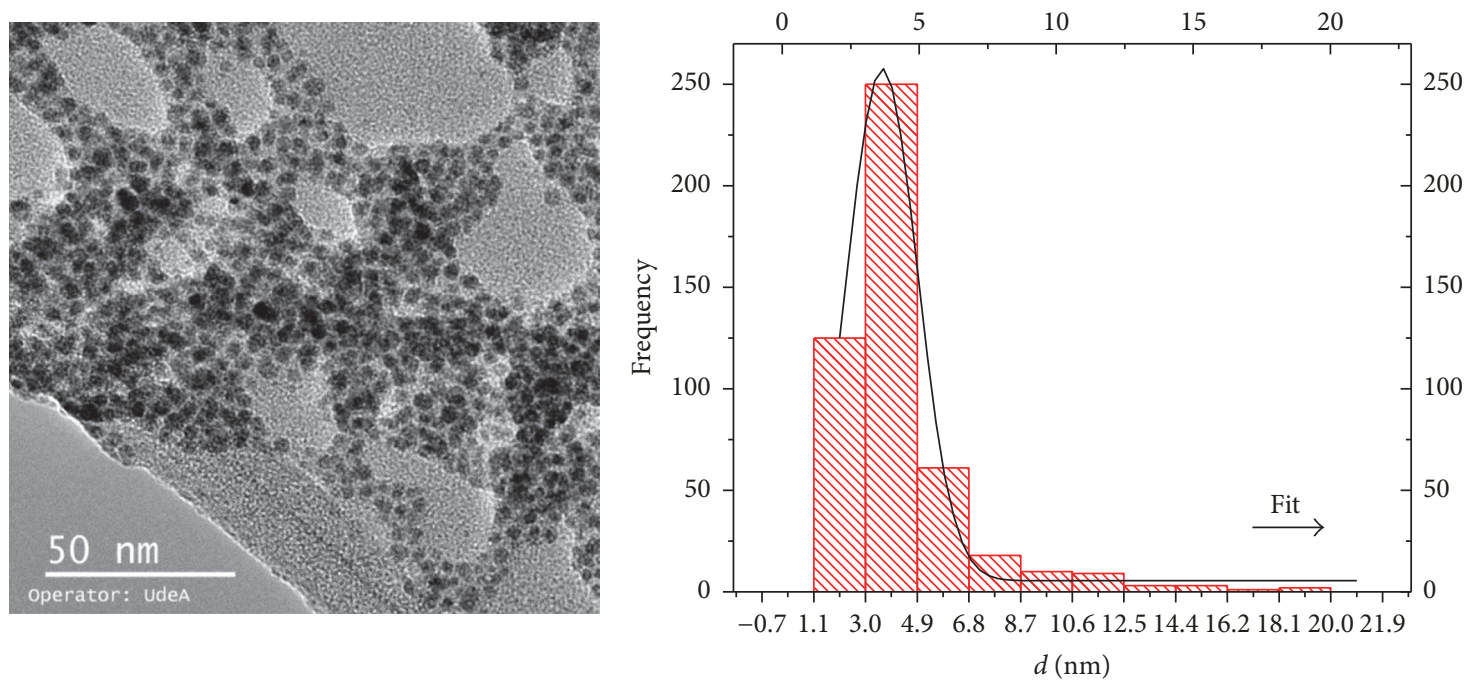

(b)

FIGURE 2: TEM micrographs of silver nanoparticles obtained from aqueous (a) or ethanolic (b) Aloe vera extracts.

TABLE 1: Planes distances of values found in this work compared with those reported in [16].

\begin{tabular}{lccccc}
\hline $2 \theta(\mathrm{grad})[17]$ & $d(\mathrm{~nm})[16]$ & $1 / d(1 / \mathrm{nm})[16]$ & Miller index & TEM $(1 / d)($ Figure 3(a)) & TEM $(1 / d)($ Figure 3(b)) \\
\hline 38.3182 & 0.235 & 4.25 & $(111)$ & 4.16 & 4.26 \\
44.4975 & 0.203 & 4.92 & $(200)$ & 4.88 & 4.87 \\
64.6119 & 0.144 & 6.94 & $(220)$ & 6.81 & 6.83 \\
77.5385 & 0.123 & 8.13 & $(311)$ & 8.05 & 8.09 \\
\hline
\end{tabular}

of solution AgNPs) into an agar medium, followed by the inoculation of a defined microbial inoculum onto the agar plate surface. Bactericidal activity was shown at higher concentration $(40,60,80$, and $100 \%)$, while at $20 \%$ dilution, there was no antibacterial activity. The lowest concentration that completely inhibited visible growth, in both extracts, was $40 \%$. Figure 4 shows photographs of the antibacterial test results. To optimize its use as a bactericide, concentrations of 20 to $40 \%$ in the extract must be evaluated in order to find the actual effective concentration in bactericidal properties for both synthesis solvents.

(ii) Mercury Removal Capacity of Synthesized AgNPs. Hg(II) removal percentage (\%) was calculated to evaluate the efficiency of silver nanoparticles synthesized using either aqueous or ethanolic Aloe vera extracts. Figure 5 shows the level of $\mathrm{Hg}$ (II) removal for both extracts, using three different initial $\mathrm{Hg}(\mathrm{II})$ concentrations and a range of AgNPs concentrations. 

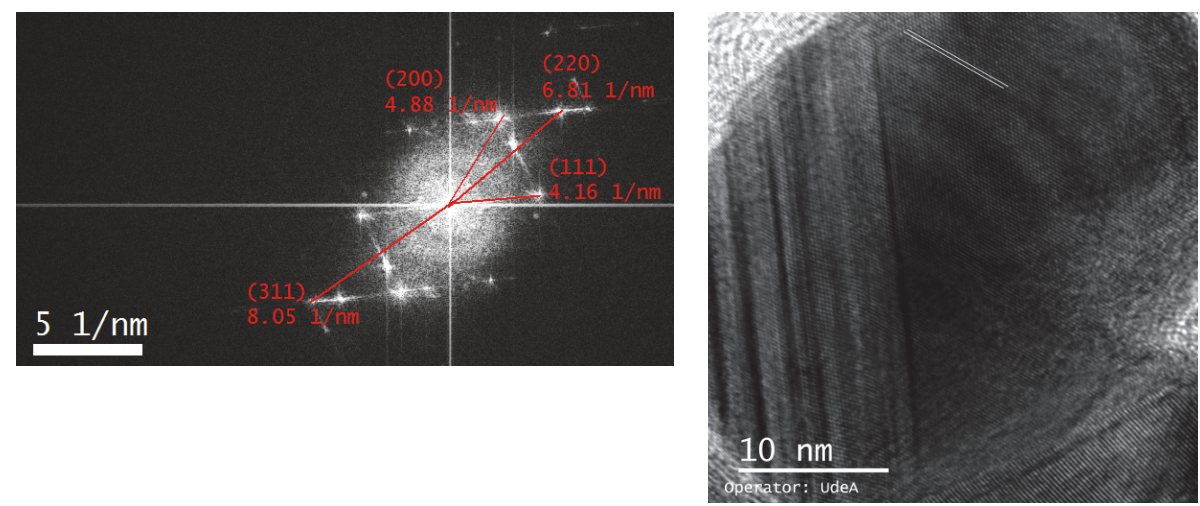

(a)
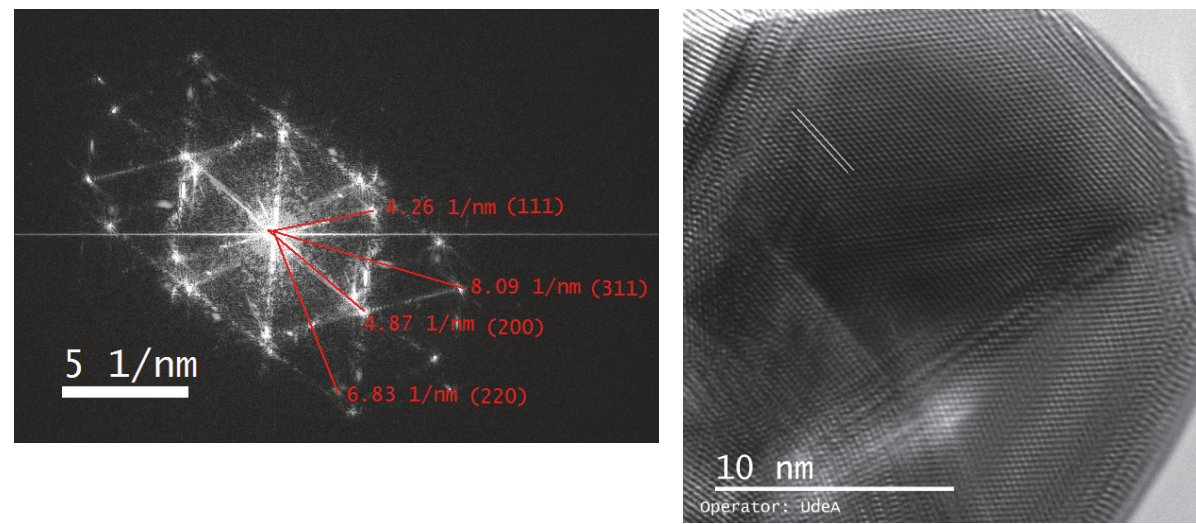

(b)

FIGURE 3: Selected area electron diffraction pattern showing the characteristic crystal planes of elemental silver: (a) aqueous Aloe vera extract; (b) ethanolic Aloe vera extract.

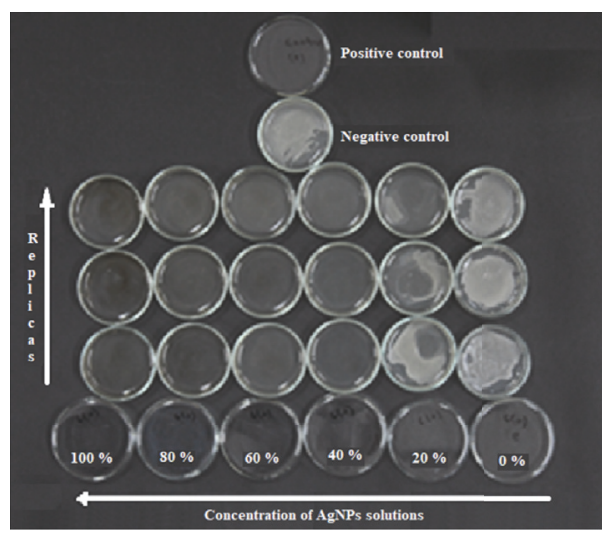

(a)

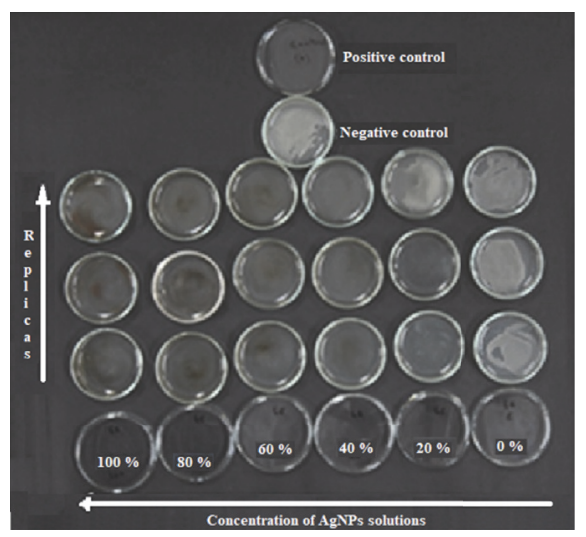

(b)

Figure 4: Photographs of the antibacterial test results of AgNPs at 100, 80, 60, 40, and 20\%, made in triplicate for both (a) aqueous Aloe vera extract and (b) ethanolic Aloe vera extract.

With a minimal concentration of Aloe vera extract $(20 \% \mathrm{~V} / \mathrm{V})$, the $\mathrm{Hg}$ (II) removal percentage of about $95 \%$ was observed for aqueous Aloe vera extract and above $96 \%$ for ethanolic Aloe vera extract, indicating the effectiveness of the two systems. Therefore, it is not necessary to use high concentrations of nanoparticles for effective removal of mercury.
Due to high toxicity effects of mercury, World Health Organization (WHO) has set the limit of mercury in drinking water as $1.0 \mathrm{mg} / \mathrm{L}(1 \mathrm{ppm})$ [28] and the United States Environmental Protection Agency (EPA) has set the limit of $2 \mathrm{mg} / \mathrm{L}$ (2 ppm) [39]. From the results shown in Figure 5, the maximum amount of mercury remaining unremoved for the 


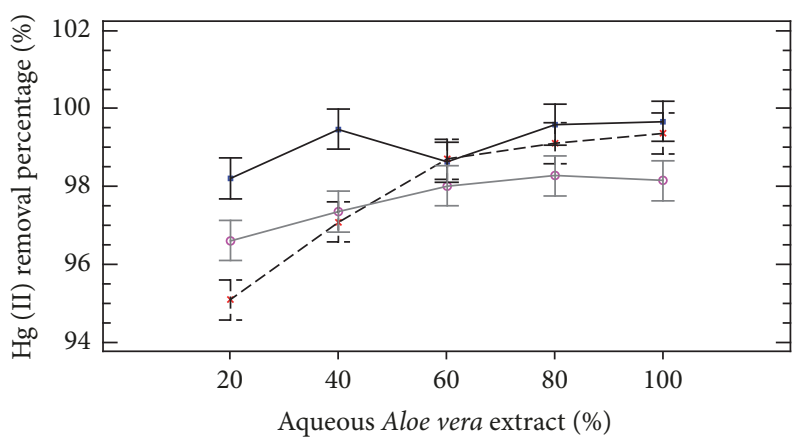

$\mathrm{Hg}$ (II)

$\rightarrow 5 \mathrm{mg} / \mathrm{L}$

-*- $10 \mathrm{mg} / \mathrm{L}$

$\multimap 15 \mathrm{mg} / \mathrm{L}$

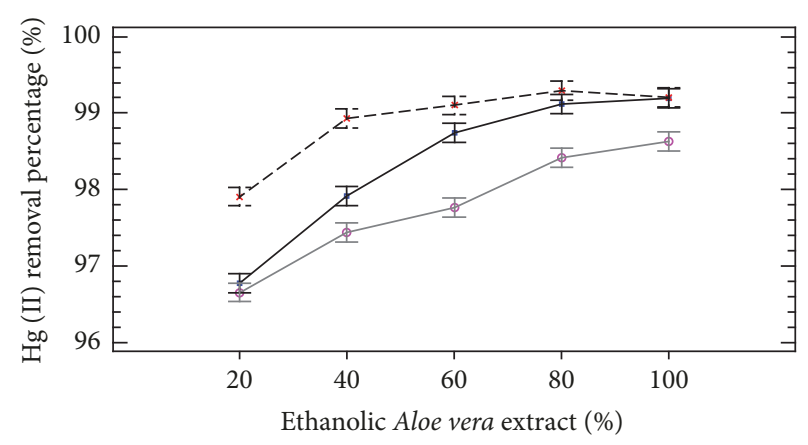

$\mathrm{Hg}$ (II)

$\longrightarrow 5 \mathrm{mg} / \mathrm{L}$
$-*-10 \mathrm{mg} / \mathrm{L}$
$\multimap 15 \mathrm{mg} / \mathrm{L}$

(a)

(b)

FIGURE 5: Mercury removal percentage at different concentration of $\mathrm{Hg}(\mathrm{II})$. (a) Aqueous Aloe vera extract and (b) ethanolic Aloe vera extract.

$20 \%$ of concentration of nanoparticles in Aloe vera extract is around $0.75 \mathrm{mg} / \mathrm{L}$, which is less than that allowed by the WHO and EPA organizations. Therefore, it is highly feasible to use AgNPs to remediate water contaminated with this metal.

\section{Conclusions}

Silver nanoparticles (AgNPs) with less than $15 \mathrm{~nm}$ size and nearly spherical shape were synthesized using aqueous and ethanolic Aloe vera extracts. Crystalline character of AgNPs was evidenced from circular spots in the electron diffraction patterns. The size distribution and lattice constants were analyzed by means of High-Resolution TEM images. These nanoparticles have bactericidal activity against Kocuria varians, since only $4 \%$ of effective concentration is enough to completely inhibit visible growth. Interestingly, synthesized AgNPs were also used for mercury removal. The $\mathrm{Hg}(\mathrm{II})$ removal percentage was above $95 \%$ just using $20 \% \mathrm{~V} / \mathrm{V}$ concentration of both extracts. This result permitted finding that the maximum amount of mercury that remained unremoved was around $0.75 \mathrm{mg} / \mathrm{L}$, which is below the levels allowed by the WHO and EPA organizations. In this research, the green synthetic method using extracts shown here gives new paths in the development of AgNPs with controlled size and shape. Moreover, due to surface modification of AgNPs by the extracts, new challenges are opened for science (biology, physics, and chemistry) in order to understand the antibacterial mechanism and action, as well as the removal phenomena and its interaction with other metals, among other complex effects.

Finally, the processes on the separation and recovery of AgNPs with $\mathrm{Hg}$ are not discussed in this paper. Research on these processes is in progress.

\section{Conflicts of Interest}

The authors declare that they have no conflicts of interest.

\section{Acknowledgments}

This work was supported by the Vicerrectoría de Investigación, Universidad de Medellín. It is also supported by Proyecto Química Verde (Code: 764). The authors gratefully acknowledge Centro de Laboratorios of Universidad de Medellín. Oscar Arnache and Jaime Osorio want to acknowledge CODI-Universidad de Antioquia for the financial support through the sustainability strategy of Solid State Group (2018-2019).

\section{References}

[1] D. K. Bhui and A. Misra, "Synthesis of worm like silver nanoparticles in methyl cellulose polymeric matrix and its catalytic activity," Carbohydrate Polymers, vol. 89, no. 3, pp. 830-835, 2012.

[2] B. Mohapatra, S. Kuriakose, and S. Mohapatra, "Rapid green synthesis of silver nanoparticles and nanorods using Piper nigrum extract," Journal of Alloys and Compounds, vol. 637, pp. 119-126, 2015.

[3] S. Ahmed, M. Ahmad, B. L. Swami, and S. Ikram, "A review on plants extract mediated synthesis of silver nanoparticles for antimicrobial applications: a green expertise," Journal of Advanced Research, vol. 7, no. 1, pp. 17-28, 2016.

[4] K. B. Narayanan and H. H. Park, "Antifungal activity of silver nanoparticles synthesized using turnip leaf extract (Brassica rapa L.) against wood rotting pathogens," European Journal of Plant Pathology, vol. 140, no. 2, pp. 185-192, 2014.

[5] P. Logeswari, S. Silambarasan, and J. Abraham, "Synthesis of silver nanoparticles using plants extract and analysis of their antimicrobial property," Journal of Saudi Chemical Society, vol. 19, no. 3, pp. 311-317, 2015.

[6] K. Shameli, M. B. Ahmad, E. A. J. Al-Mulla et al., "Green biosynthesis of silver nanoparticles using Callicarpa maingayi stem bark extraction," Molecules, vol. 17, no. 7, pp. 8506-8517, 2012.

[7] T. N. J. I. Edison, Y. R. Lee, and M. G. Sethuraman, "Green synthesis of silver nanoparticles using Terminalia cuneata and its catalytic action in reduction of direct yellow-12 dye," Spectrochimica Acta Part A: Molecular and Biomolecular Spectroscopy, vol. 161, pp. 122-129, 2016. 
[8] C. Luna, V. H. G. Chávez, E. D. Barriga-Castro, N. O. Núñez, and R. Mendoza-Reséndez, "Biosynthesis of silver fine particles and particles decorated with nanoparticles using the extract of Illicium verum (star anise) seeds," Spectrochimica Acta Part A: Molecular and Biomolecular Spectroscopy, vol. 141, pp. 43-50, 2015.

[9] T. N. J. I. Edison and M. G. Sethuraman, "Electrocatalytic reduction of benzyl chloride by green synthesized silver nanoparticles using pod extract of Acacia nilotica," ACS Sustainable Chemistry \& Engineering, vol. 1, no. 10, pp. 1326-1332, 2013.

[10] S. P. Chandran, M. Chaudhary, R. Pasricha, A. Ahmad, and M. Sastry, "Synthesis of gold nanotriangles and silver nanoparticles using Aloe vera plant extract," Biotechnology Progress, vol. 22, no. 2, pp. 577-583, 2006.

[11] S. Medda, A. Hajra, U. Dey, P. Bose, and N. K. Mondal, "Biosynthesis of silver nanoparticles from Aloe vera leaf extract and antifungal activity against Rhizopus sp. and Aspergillus sp.", Applied Nanoscience, vol. 5, no. 7, pp. 875-880, 2015.

[12] D. Dinesh, K. Murugan, P. Madhiyazhagan et al., "Mosquitocidal and antibacterial activity of green-synthesized silver nanoparticles from Aloe vera extracts: towards an effective tool against the malaria vector Anopheles stephensi?" Parasitology Research, vol. 114, no. 4, pp. 1519-1529, 2015.

[13] Y. Zhang, D. Yang, Y. Kong, X. Wang, O. Pandoli, and G. Gao, "Synergetic antibacterial effects of silver Nanoparticles@Aloe vera prepared via a green method," Nano Biomedicine and Engineering, vol. 2, no. 4, pp. 252-257, 2010.

[14] T. M. D. Dang, T. T. T. Le, E. Fribourg-Blanc, and M. C. Dang, "Synthesis and optical properties of copper nanoparticles prepared by a chemical reduction method," Advances in Natural Sciences: Nanoscience and Nanotechnology, vol. 2, no. 1, Article ID 015009, 2011.

[15] U. Nandal and R. L. Bhardwaj, "Aloe vera: a valuable wonder plant for food, medicine and cosmetic use-a review," International Journal of Pharmaceutical Sciences Review and Research, vol. 13, no. 1, pp. 59-67, 2012.

[16] T. Theivasanthi and M. Alagar, "Electrolytic synthesis and characterization of silver nanopowder," Nano Biomedicine and Engineering, vol. 4, no. 2, pp. 58-65, 2012.

[17] J.-X. Wang, L.-X. Wen, Z.-H. Wang, and J.-F. Chen, "Immobilization of silver on hollow silica nanospheres and nanotubes and their antibacterial effects," Materials Chemistry and Physics, vol. 96, no. 1, pp. 90-97, 2006.

[18] C. Marambio-Jones and E. M. V. Hoek, "A review of the antibacterial effects of silver nanomaterials and potential implications for human health and the environment," Journal of Nanoparticle Research, vol. 12, no. 5, pp. 1531-1551, 2010.

[19] M. A. Shenashen, S. A. El-Safty, and E. A. Elshehy, "Synthesis, morphological control, and properties of silver nanoparticles in potential applications," Particle \& Particle Systems Characterization, vol. 31, no. 3, pp. 293-316, 2014.

[20] T. Pradeep and Anshup, "Noble metal nanoparticles for water purification: a critical review," Thin Solid Films, vol. 517, no. 24, pp. 6441-6478, 2009.

[21] A. A. Becaro, F. C. Puti, A. R. Panosso et al., "Postharvest quality of fresh-cut carrots packaged in plastic films containing silver nanoparticles," Food and Bioprocess Technology, vol. 9, no. 4, pp. 637-649, 2016.

[22] N. Durán, P. D. Marcato, G. I. H. De Souza, O. L. Alves, and E. Esposito, "Antibacterial effect of silver nanoparticles produced by fungal process on textile fabrics and their effluent treatment," Journal of Biomedical Nanotechnology, vol. 3, no. 2, pp. 203-208, 2007.
[23] S. Zhang, Y. Tang, and B. Vlahovic, "A review on preparation and applications of silver-containing nanofibers," Nanoscale Research Letters, vol. 11, no. 1, article 80, 2016.

[24] C. I. Contescu and K. Putyera, Dekker Encyclopedia of Nanoscience and Nanotechnology, vol. 6, CRC Press, 2nd edition, 2008.

[25] K. Rajaram, D. C. Aiswarya, and P. Sureshkumar, "Green synthesis of silver nanoparticle using Tephrosia tinctoria and its antidiabetic activity," Materials Letters, vol. 138, pp. 251-254, 2015.

[26] G. Manimegalai, S. Shantha Kumar, and C. Sharma, "Pesticide mineralization in water using silver nanoparticles," International Journal of Chemical Sciences, vol. 9, no. 3, pp. 1463-1471, 2011.

[27] M. S. Bootharaju and T. Pradeep, "Uptake of toxic metal ions from water by naked and monolayer protected silver nanoparticles: An x-ray photoelectron spectroscopic investigation," The Journal of Physical Chemistry C, vol. 114, no. 18, pp. 8328-8336, 2010.

[28] E. Sumesh, M. S. Bootharaju, and T. Pradeep, "A practical silver nanoparticle-based adsorbent for the removal of $\mathrm{Hg}^{2+}$ from water," Journal of Hazardous Materials, vol. 189, no. 1-2, pp. 450457, 2011.

[29] K. V. Katok, R. L. D. Whitby, T. Fukuda et al., "Hyperstoichiometric interaction between silver and mercury at the nanoscale," Angewandte Chemie International Edition, vol. 51, no. 11, pp. 2632-2635, 2012.

[30] A. Esmaielzadeh Kandjani, Y. M. Sabri, M. Mohammad-Taheri, V. Bansal, and S. K. Bhargava, "Detect, remove and reuse: A new paradigm in sensing and removal of $\mathrm{Hg}$ (II) from wastewater via SERS-active $\mathrm{ZnO} / \mathrm{Ag}$ nanoarrays," Environmental Science \& Technology, vol. 49, no. 3, pp. 1578-1584, 2015.

[31] E. C. Gloria, V. Ederley, M. Gladis et al., "Synthesis of silver nanoparticles (AgNPs) with antibacterial activity," Journal of Physics: Conference Series, vol. 850, no. 1, Article ID 012023, 2017.

[32] W. S. Rasband, ImageJ, U.S. National Institutes of Health, Bethesda, Md, USA, 1997-2016, http://imagej.nih.gov/ij/.

[33] I. Siegert and C. Banks, "The effect of volatile fatty acid additions on the anaerobic digestion of cellulose and glucose in batch reactors," Process Biochemistry, vol. 40, no. 11, pp. 3412-3418, 2005.

[34] S. Purty, R. Saranathan, K. Prashanth et al., "The expanding spectrum of human infections caused by Kocuria species: a case report and literature review," Emerging Microbes \& Infections, vol. 2, no. 10, article e71, 2013.

[35] V. Kandi, P. Palange, R. Vaish et al., "Emerging bacterial infection: identification and clinical significance of Kocuria species," Cureus, vol. 8, article e731, 2016.

[36] C.-Y. Tsai, S.-H. Su, Y.-H. Cheng, Y.-L. Chou, T.-H. Tsai, and A.-S. Lieu, "Kocuria varians infection associated with brain abscess: a case report," BMC Infectious Diseases, vol. 10, article 102, 2010.

[37] J. Benites, Z. Ayala, and J. Málaga, "Reporte de un caso de infección urinaria por kocuria varians," Revista de Investigación de la Universidad Norbert Wiener, no. 4, pp. 33-36, 2015.

[38] S. Sobhani and Z. Pakdin-Parizi, "Palladium-DABCO complex supported on $\gamma$-Fe2O3 magnetic nanoparticles: A new catalyst for CC bond formation via Mizoroki-Heck cross-coupling reaction," Applied Catalysis A: General, vol. 479, pp. 112-120, 2014.

[39] National Recommended Water Quality Criteria for Priority Toxic Pollutants, Document EPA-Z-99-01, U.S. Environmental Protection Agency, 2010. 


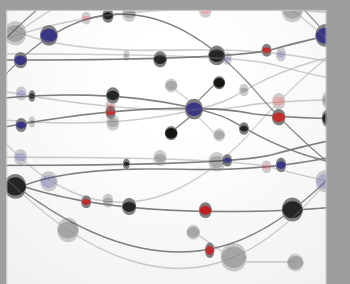

The Scientific World Journal
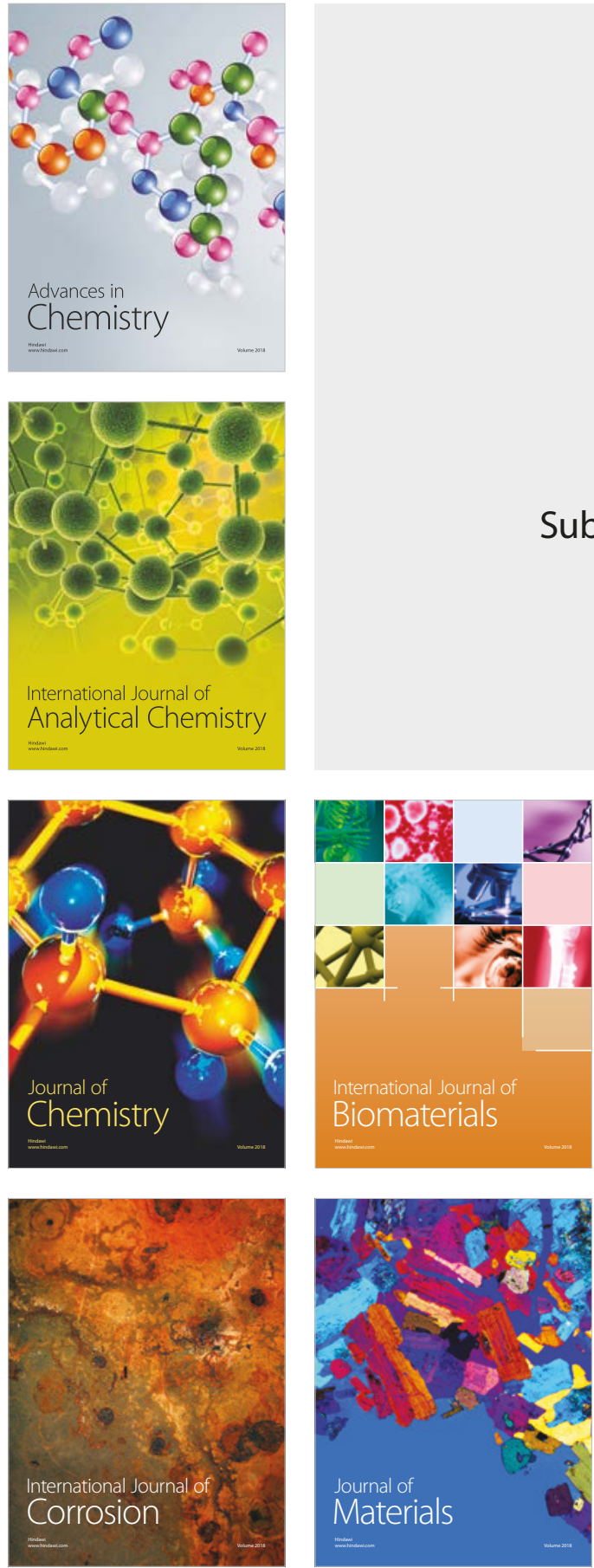

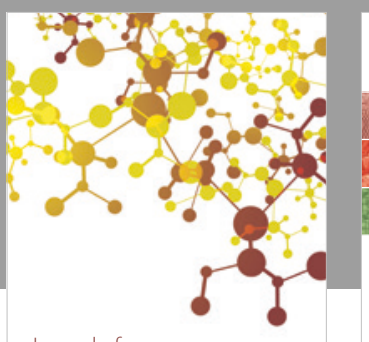

Journal of

Applied Chemistry
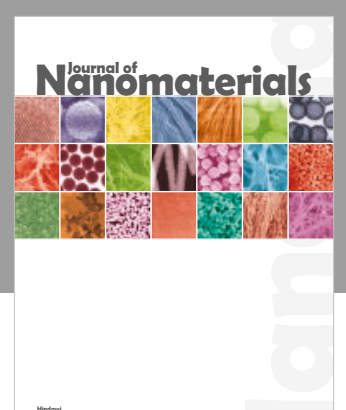

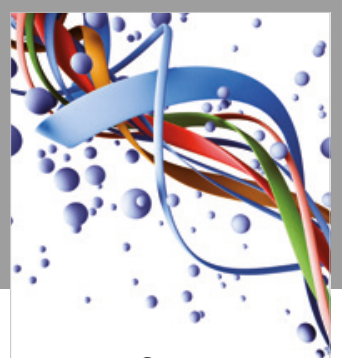

Scientifica

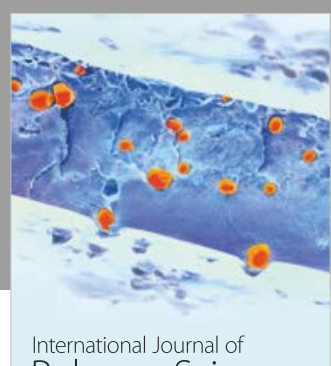

Polymer Science

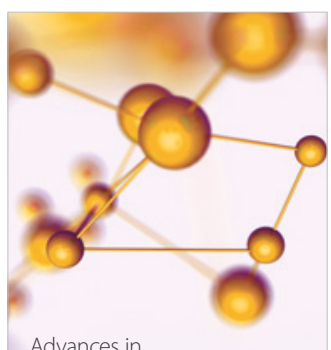

Physical Chemistry
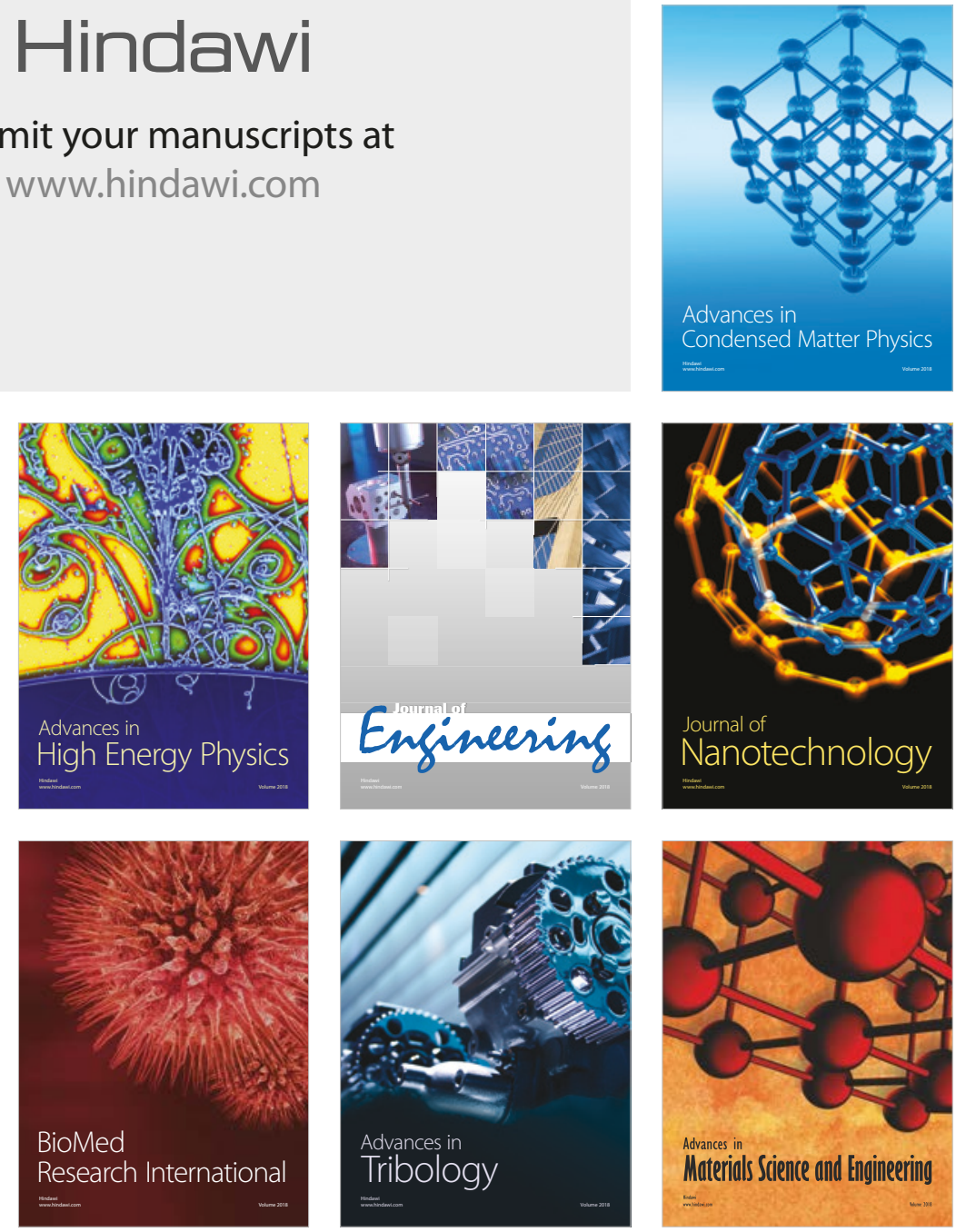